\title{
High 24-Hour Respiratory Symptoms and Low Physical Activity in the Stable COPD Romanian Cohort of SPACE Study
}

\author{
Florin Mihaltan' \\ Ruxandra- \\ Mioara Rajnoveanu (iD ${ }^{2}$ \\ Oana Cristina Arghir (iD) ${ }^{3}$ \\ Silviu Alecu (D) ${ }^{4}$ \\ Paraschiva A Postolache ${ }^{5}$ \\ 'Pneumology Department, "Carol Davila" \\ University of Medicine and Pharmacy, \\ Bucharest, Romania; ${ }^{2}$ Pneumology \\ Department, "Iuliu Hatieganu" University of \\ Medicine and Pharmacy, Cluj-Napoca, Romania; \\ ${ }^{3}$ Faculty of Medicine, "Ovidius" University of \\ Constanta, Constanta, Romania; ${ }^{4}$ AstraZeneca \\ Romania, Bucharest, Romania; ${ }^{5}$ Medical \\ Department, "Grigore T. Popa" University of \\ Medicine and Pharmacy, lasi, Romania
}

\section{Video Abstract}

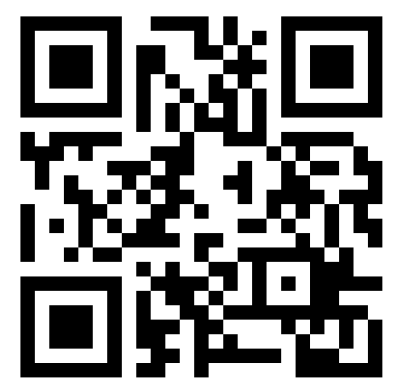

Point your SmartPhone at the code above. If you have a $Q R$ code reader the video abstract will appear. Or use: https://youtu.be/MewWVe3P-Jc.

Correspondence: Ruxandra-Mioara Rajnoveanu

Department of Pulmonology, "luliu Hatieganu" University of Medicine and Pharmacy, B.P. Hasdeu Street No. 6, ClujNapoca, 40037I, Romania

Tel/Fax +40264597453 Ext. I2I

Email andra_redro@yahoo.com
Objective: This study assessed the characteristics and the relationship between symptoms in any part of the 24-hour (24-h) day, physical activity level (PAL), and other clinical and functional outcomes in stable COPD patients.

Patients and Methods: Out of the 2162 patients enrolled in the SPACE study (The Symptoms and Physical Activity in COPD patients in Europe, clinicaltrials.gov NCT03031769), 406 (18.8\%) were recruited from Romania. Here, we present the Romanian cohort results. Eligible patients were adults with age at least 40 years, confirmed diagnosis of stable COPD, current or former smokers with a smoking history of minimum 10 pack-years. The 24-h respiratory symptoms were assessed using Early Morning Symptoms of COPD Instrument (EMSCI), Evaluating Respiratory Symptoms in COPD (E-RS ${ }^{\mathrm{TM}}$ : COPD) and Nighttime Symptoms of COPD Instrument (NiSCI). During clinical interview, patients self-evaluated PAL through Exercise as Vital Sign (EVS) and Yale Physical Activity Survey (YPAS). Physicians assessed PAL through their clinical judgment.

Results: For each combination of 2 between the early morning (EM), daytime (DT) and night-time (NT) symptoms of the 24-h day, there was a significant association $(\mathrm{p}<0.001$ for each). All symptoms significantly correlated with exacerbation history $(\mathrm{p}<0.001$ for EM and NT, $p=0.002$ for DT), and number of severe exacerbations $(p<0.001$ for DT, $p=0.001$ for $\mathrm{EM}$ and $\mathrm{p}=0.026$ for NT, respectively). The 24-h symptoms correlated negatively and significantly with PAL $(\mathrm{p}<0.001)$, irrespective of the assessment used. Self-reported PAL negatively correlated with dyspnea, symptom burden, severity of disease and number of exacerbations $(\mathrm{p}<0.001)$. Patients spent an average (standard deviation) of 25.8 (21.0) hours/week performing physical activity. Physicians overestimated their patients' daily PAL. Conclusion: A negative and significant correlation between the 24-h day symptoms and PAL was identified in stable COPD patients. Physicians need to routinely assess PAL using adequate tools and start educating inactive COPD patients to optimize their disease outcomes.

Keywords: COPD, respiratory symptoms, physical activity

\section{Introduction}

With significant morbidity and mortality, Chronic Obstructive Pulmonary Disease (COPD) is an important public health burden worldwide, despite being considered preventable and treatable. ${ }^{1}$ The Global Initiative for Obstructive Lung Disease (GOLD) launched the combined assessment in 2011, when symptom burden was added to the previous spirometric grading system of pulmonary function and history of exacerbations. $^{2}$ Through this multidimensional GOLD assessment, the clinicians 
could classify patients into four quadrants (ABCD), which allowed making more individualized treatment decisions. GOLD ABCD classification system was further simplified in 2017, when spirometric measures were removed from the combined assessment, leaving only the respiratory symptoms and exacerbation history. ${ }^{3}$

The negative impact of COPD symptom burden on patients' routine activities, health-related and overall quality of life has been previously demonstrated. ${ }^{4-11}$ The perceived symptoms vary throughout the 24-hour (24-h) day ${ }^{4,5,7-11}$ and do not correlate with the level of airflow limitation. ${ }^{6}$ Frequently, COPD patients need to reduce their level of physical activity and tend to underestimate the symptom burden. ${ }^{1}$ Moreover, a downward spiral of inactivity induced by symptoms characterizes COPD. ${ }^{12}$ Previous studies have shown that physical inactivity leads to a higher risk of hospitalizations, exacerbations and mortality and a reduced healthrelated quality of life in COPD patients, although the exact relationship between various clinical and functional indicators and physical activity is not yet elucidated. ${ }^{13-15}$ In consequence, increasing physical activity has the potential of being one key nonpharmacological interventions in COPD patients, irrespective of the specific ABCD group. ${ }^{1}$

In Romania, the respiratory symptoms (RS) were explored in several national COPD awareness campaigns that showed an increasing prevalence of lung function impairment. ${ }^{16,17}$ However, the daily variability and the impact of symptoms in stable COPD were not assessed so far in depth. Several local studies showed a low physical activity level (PAL) of patients with COPD,${ }^{18-20}$ a finding in line with data reported in the literature, ${ }^{21-24}$ but less is known about the $R S$ burden, patterns of physical activity and their relationship in stable COPD patients from Romania.

\section{Objectives}

The overarching primary objective of this study was to describe the prevalence and severity of early morning (EM), daytime (DT) and night-time (NT) symptoms of the 24-h day, and the patterns of physical activity in COPD stable patients. The secondary objectives of the study were to explore the relationship between the 24$\mathrm{h}$ day symptoms and PAL and other COPD clinical and functional dimensions including, without being limited to, level of dyspnea, health status, comorbidities, severity of disease, and exacerbation history.

\section{Materials and Methods Study Design}

The multinational, multicenter, observational, cross-sectional study of Symptoms and Physical Activity in COPD patients in Europe (SPACE, NCT03031769) was performed in 10 European countries and Israel and enrolment lasted for 9 months (from December 2016 to August 2017). From Romania, 17 pulmonary centers participated to this study. This paper presents the results of the Romanian cohort of patients with stable COPD enrolled in SPACE study.

Details on the study design have been already reported, ${ }^{25}$ but this is the first evaluation of the Romanian COPD cohort of patients. This study had a single visit to collect data (eg, socio-demographic data, smoking history, comorbidities, year of COPD diagnosis, current COPD treatment, spirometry information, number, type and number of exacerbations and COPD-related healthcare resource use in the previous 12 months) from medical charts or during clinical interview with COPD patients. The definition of exacerbation used in the study was: an acute worsening of respiratory symptoms that resulted in additional therapy, eg, bronchodilators only (mild exacerbation), bronchodilators plus antibiotics and/or oral corticosteroids (moderate exacerbation) or required hospitalization or emergency room visits (severe exacerbation).

Based on all data collected in the study, several parameters were determined (COPD specific comorbidities test [COTE] index, ${ }^{26}$ combined index of body mass index, spirometry assessment of the presence and severity of air flow obstruction, dyspnea and exacerbations [BODEx]). ${ }^{27}$ Patients were divided into $\mathrm{ABCD}$ groups according to GOLD $2013^{28}$ and $2017^{3}$ recommendations, the latter guide being in use at the time of the study.

The Romanian National Bioethics Committee of Medicines and Medical Devices approved the study at central level (approval number 29SNI/21.11.2016). This study was conducted in accordance with the Declaration of Helsinki. All COPD patients expressed their written informed consent before enrollment.

\section{Patients}

The study population consisted of COPD patients aged $\geq 40$ years, with $\geq 1$ year since diagnosis and stable disease defined by no exacerbation history or any change in current COPD maintenance treatment in the last two months before enrolment. Other inclusion criteria referred to 
smoking history of at least 10 pack-years and documented post-bronchodilator forced expiratory volume in 1 second/ forced vital capacity $\left(\mathrm{FEV}_{1} / \mathrm{FVC}\right)$ ratio of $<0.7$ in the year before enrolment. Other chronic respiratory disorders besides COPD or sleep apnea syndrome, any acute or chronic disease that would have altered the ability to complete the questionnaires, and concomitant inclusion in a clinical trial that would have influenced participation in the SPACE study represented exclusion criteria. Patients previously diagnosed with asthma or non-idiopathic pulmonary fibrosis could participate in SPACE study only if COPD was the primary documented diagnosis.

\section{Assessments}

The patients participating to SPACE study completed several interviewer- and patient-administered questionnaires Dyspnea assessment was performed using the modified Medical Research Council (mMRC) scale. ${ }^{29}$ The COPD Assessment Test (CAT) was utilized to determine the health status and symptomatic impact of COPD. ${ }^{30}$ The thresholds for separating the low- and high-symptom burden groups in the GOLD ABCD assessment were $\geq 2$ for $\mathrm{mMRC}$ and $\geq 10$ points for $\mathrm{CAT}^{2,3}$

COPD symptoms were assessed using specific, validated questionnaires for early morning, daytime and nighttime periods: Early Morning Symptoms of COPD Instrument (EMSCI), ${ }^{31}$ Evaluating Respiratory Symptoms in COPD (E-RS $\left.{ }^{\mathrm{TM}}: \mathrm{COPD}\right),{ }^{32}$ and Nighttime and Symptoms of COPD Instrument (NiSCI). ${ }^{33}$ For EMSCI and NiSCI questionnaires, responses were coded from 0 to 4 , using 0 for "no symptoms" and 4 for "very severe symptoms". The overall severity score and 6-item severity scores were calculated. For the E-RS ${ }^{\mathrm{TM}}$ : COPD questionnaire, the $R S$ were quantified using total score (RS-Total score), with values from 0 to 40 , higher scores meaning more severe symptoms.

For the PAL assessment, physicians used their clinical judgment to estimate the level of physical activity for their patients and classify them as active (performing $\geq 150$ minutes/week of moderate to vigorous exercise such as brisk walk), insufficiently active (1-149 minutes/week of moderate to vigorous exercise) or inactive ( 0 minutes/ week of moderate to vigorous activity). ${ }^{34}$ At study visit, patients were asked to self-evaluate their PAL. Within this scope, two questions originating in the Exercise as Vital Sign (EVS) program ${ }^{35}$ (Supplemental Table S1) and the Investigator-administered Yale Physical Activity Survey $(\text { YPAS })^{36}$ were included in the clinical interview.

\section{Statistical Analysis}

The database included all eligible patients enrolled in the study. Descriptive statistics were performed using version 3.3.3 of the $\mathrm{R}$ package (https://www.r-project.org/)1 The analysis included Student's $t$ and Wilcoxon signed rank tests for the exploration of the differences in means and distributions between independent groups. The relationships of symptoms or physical activity levels with COPD clinical and functional indicators (level of dyspnea, disease severity, and COPD exacerbations), comorbidities, and impact on physical activities were evaluated using the Pearson correlation coefficient for continuous variables or Spearman correlation coefficient for ordinal variables. All statistical tests were two-sided and used a 5\% significance level.

\section{Results}

\section{Patients' Characteristics}

The Romanian cohort of patients enrolled in SPACE consisted in 406 cases (18.8\%), with a mean age of 65.9 years, and predominantly males (85\%) (Table 1). Most patients reported dyspnea of grade $\geq 2$ on mMRC scale (72.4\%) and a CAT score $\geq 10(86.7 \%)$. The most frequently reported non-respiratory comorbidities were of cardio-vascular nature: hypertension (63.3\%), coronary heart disease (33.5\%), and chronic heart failure (19.5\%). Respiratory comorbidities included non-idiopathic pulmonary fibrosis (7.1\%), while a previous diagnosis of asthma was noticed in $6.7 \%$ of cases. One third of patients (32.8\%) reported influenza flu vaccine performed in the last year and just a minority $(2.7 \%)$ received the pneumococcal vaccine (Supplemental Table S2).

The proportion of patients classified in $\mathrm{ABCD}$ groups differed by edition (GOLD 2013 or GOLD 2017) and within each edition according to the cut-off point of mMRC grade $\geq 2$ or CAT score $\geq 10$ (Figure 1A and B). The percentage of patients in group B increased from $16.0 \%$ by GOLD 2013 edition to $32.0 \%$ by GOLD 2017 edition when using mMRC, and from $19.5 \%$ to $40.9 \%$ when using CAT, respectively. The proportion of patients having high symptom burden $(\mathrm{B}+\mathrm{D})$ remained constant between editions when the same $A B C D$ assessment tool was used but differed between tools: $72.4 \%$ patients classified by $\mathrm{mMRC}$ in $\mathrm{B}+\mathrm{D}$ groups in contrast to $86.7 \%$ by CAT.

\section{Respiratory Symptoms}

In total, $87.7 \%$ of patients presented at least one EM symptom, $71.4 \%$ at least one NT symptom and $92.6 \%$ at 
Table I Socio-Demographic and Clinical Characteristics of Patients

\begin{tabular}{|c|c|}
\hline Characteristic & $N=406$ \\
\hline Males, n (\%) & $339(83.5)$ \\
\hline Age, mean (SD), years & $65.9(8.5)$ \\
\hline \multicolumn{2}{|l|}{ Educational level, n (\%) } \\
\hline Primary school & $42(10.3)$ \\
\hline Secondary school & $|4|(34.7)$ \\
\hline High-school & $172(42.4)$ \\
\hline University and post-university education & $51(12.6)$ \\
\hline \multicolumn{2}{|l|}{ Employment status, n (\%) } \\
\hline Retired & $309(76.1)$ \\
\hline Employed & $28(6.9)$ \\
\hline Unemployed & $3(0.7)$ \\
\hline Other & $7(1.7)$ \\
\hline \multicolumn{2}{|l|}{ Smoking history } \\
\hline Active smokers, n (\%) & $96(23.6)$ \\
\hline Former smokers, n (\%) & $310(76.4)$ \\
\hline Pack-years, mean (SD) & $38.1(23.8)$ \\
\hline$\%$ predicted $\mathrm{FEV}_{1}$, mean (SD) & $47.82(16.2)$ \\
\hline Post-BD FEV $/$ FVC, mean (SD) & $0.55(0.1)$ \\
\hline \multicolumn{2}{|l|}{ COPD severity, n (\%) } \\
\hline GOLD group I (mild) & II (2.7) \\
\hline GOLD group II (moderate) & $176(43.3)$ \\
\hline GOLD group III (severe) & $164(40.4)$ \\
\hline GOLD group IV (very severe) & $55(13.5)$ \\
\hline \multicolumn{2}{|l|}{$\mathrm{mMRC}$} \\
\hline mMRC 0-I, n (\%) & $112(27.6)$ \\
\hline $\mathrm{mMRC} \geq 2, \mathrm{n}(\%)$ & $294(72.4)$ \\
\hline \multicolumn{2}{|l|}{ CAT } \\
\hline CAT score, mean (SD) & I8.97 (8.2) \\
\hline CAT $<10$ & $54(13.3)$ \\
\hline CAT $\geq 10$ & $362(86.7)$ \\
\hline COTE index, mean (SD) & $1.4 \mid(1.9)$ \\
\hline BODEx index, mean (SD) & $3.04(1.8)$ \\
\hline $\begin{array}{l}\text { Mean number of comorbidities per patient, mean } \\
\text { (SD) }\end{array}$ & $1.33(1.0)$ \\
\hline \multicolumn{2}{|l|}{ Exacerbations in previous 12 months } \\
\hline History of exacerbations, $\mathrm{n}(\%)$ & $282(69.5)$ \\
\hline $\begin{array}{l}\text { Number of COPD exacerbations/patient, mean } \\
\text { (SD) }\end{array}$ & $1.97(2.7)$ \\
\hline History of severe exacerbations in last year, $\mathrm{n}(\%)$ & $75(18.5)$ \\
\hline Number of mild exacerbations/patient, mean (SD) & $0.29(0.7)$ \\
\hline
\end{tabular}

Abbreviations: BD, bronchodilator; BODEx, body mass index, obstruction, dyspnea and exacerbations; CAT, COPD Assessment Test; COPD, Chronic Obstructive Pulmonary Disease; COTE, COPD specific comorbidities test; FEV Forced Expiratory Volume in I second; FVC, Forced Vital Capacity; GOLD, Global Initiative for Chronic Obstructive Lung Disease; mMRC, modified Medical Research Council; SD, standard deviation. least one DT symptom. During night-time, $36.0 \%$ of patients were awakened by their RS. Most of individual $R S$ were mild or moderate (Figure 2). The mean RS-total score (standard deviation) was $12.6(8.1)$, overall NiSCI symptom summary score 0.9 (1.0) and overall EMSCI symptom summary score $1.4(0.9)$.

\section{Physical Activity Level}

The Investigators' assessment (clinical judgment) and patients' self-assessment (EVS questions) of PAL showed discrepant results: $37.2 \%$ of patients considered themselves inactive and $23.9 \%$ active, while physicians considered inactive $<10 \%$ of patients and active $54.4 \%$ (Figure 3 ).

The analysis of the YPAS checklist of activities showed that patients spent an average (SD) of 25.8 (21.0) hours/week performing physical activity, with a total mean energy expenditure (SD) of 5685.0 (4841.1) $\mathrm{kcal} /$ week and mean summary index of 45.3 (24.6) (Table 2).

\section{Relationship Between Respiratory Symptoms and Physical Activity or Other Outcomes}

A significant correlation was found between EM, DT and NT $R S$ and physical activity $(\mathrm{p}<0.001)$, irrespective of the assessment tool used (eg, Investigator's assessment, EVS or YPAS total score); however, the correlations were weak (the maximum value of the coefficient of determination was 0.114 for the correlation between DT $R S$ and Investigator's assessment of PAL). A significant association between EM, DT and NT RS was described for each combination of symptoms $(\mathrm{p}<0.001)$. Each type of symptom correlated significantly with CAT, mMRC, BODEx index and number of exacerbations $(\mathrm{p}<0.001)$. All $R S$ correlated significantly with history of prior exacerbations ( $\mathrm{p}<0.001$ for EM and NT symptoms, and $\mathrm{p}=0.002$ for DT symptoms), and with the number of severe exacerbations $(\mathrm{p}<0.001$ for DT, $\mathrm{p}=0.001$ for EM symptoms, and $\mathrm{p}=0.026$ for NT symptoms, respectively) (Table 3). Self-reported physical activity either using EVS or YPAS total score correlated negatively with CAT, mMRC, BODEx index and number of exacerbations $(\mathrm{p}<0.001)$ (Table 4).

\section{Discussion}

To our knowledge, this is the first detailed analysis of respiratory symptoms throughout the $24-\mathrm{h}$ day in 
A

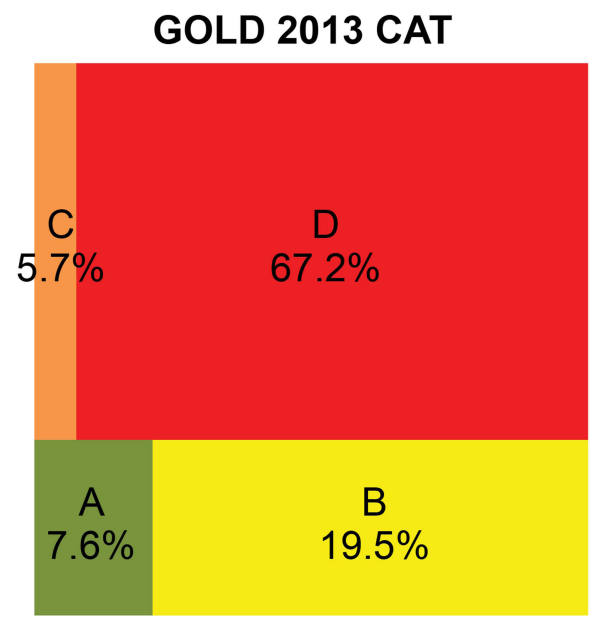

B

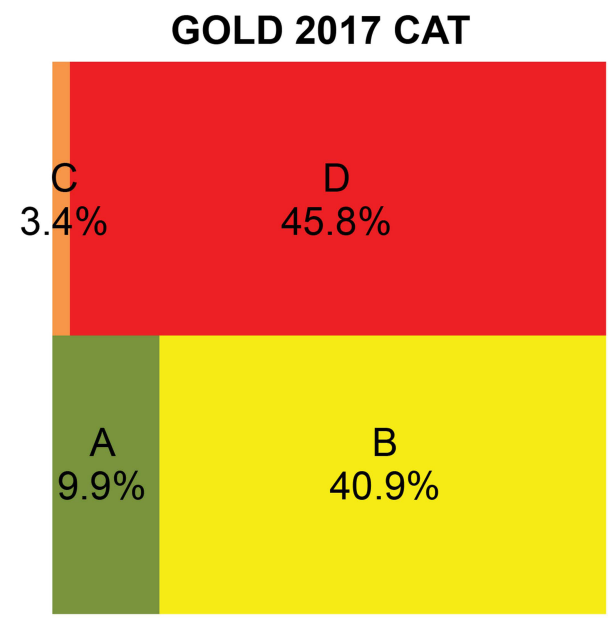

GOLD 2013 mMRC

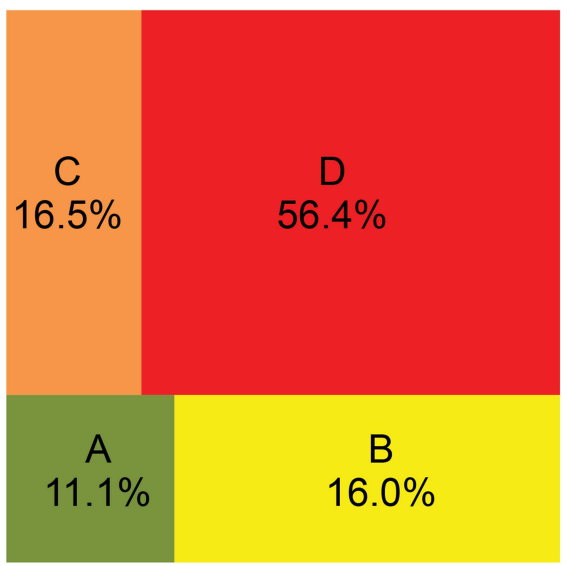

\section{GOLD 2017 mMRC}

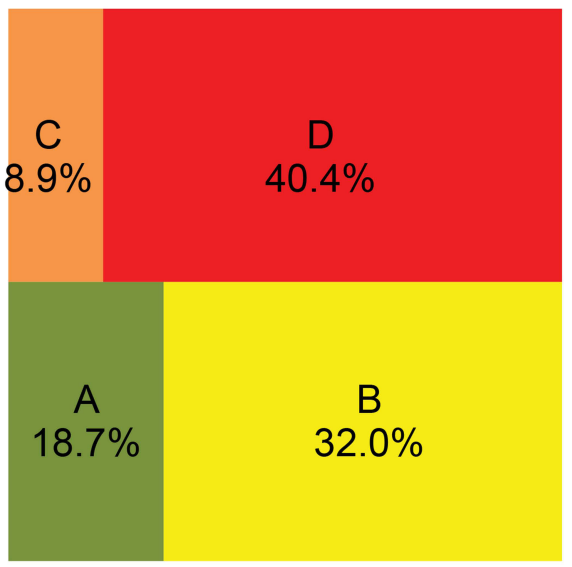

Figure I Distribution of patients in ABCD groups using the 2013 (A) and 2017 (B) GOLD edition.

Abbreviations: CAT, COPD Assessment Test; GOLD, Global Initiative for Chronic Obstructive Lung Disease; mMRC, modified Medical Research Council.

a Romanian cohort of stable COPD patients. Despite being under treatment, patients reported symptoms in any part of the 24-h day.

Considered for a long time mostly a feature of asthma, the variability of $R S$ in COPD was in depth explored in the last decade. The symptoms perceived by patients may vary in number and intensity over the course of a week or a day. ${ }^{5,7}$ Previous studies showed that nocturnal symptoms are usually under-reported and less taken into consideration in the general management of COPD, although they affect the patients' sleep quality, daily activities and overall health status, and are additionally correlating with a higher risk of cardiovascular adverse outcomes. ${ }^{10,37}$
Increased variability of COPD symptoms (mainly dyspnea) is associated with their severity, it indicates respiratory impairment and leads to exercise limitation. ${ }^{5}$ In our group of patients, the presence of early-morning, diurnal and nocturnal symptoms correlated significantly with the reported low level of physical activity, irrespective of the assessment used. Consistent to other reports, ${ }^{5,7}$ in the Romanian and overall SPACE study cohorts, ${ }^{25}$ the 24 $\mathrm{h}$ day symptoms impacted the patients' ability to perform their routine activities involving effort, from walking up and down stairs to doing sport or hobbies or performing intense housework chores. This negative relationship is hard to break, because dyspnea is the major key limitation 


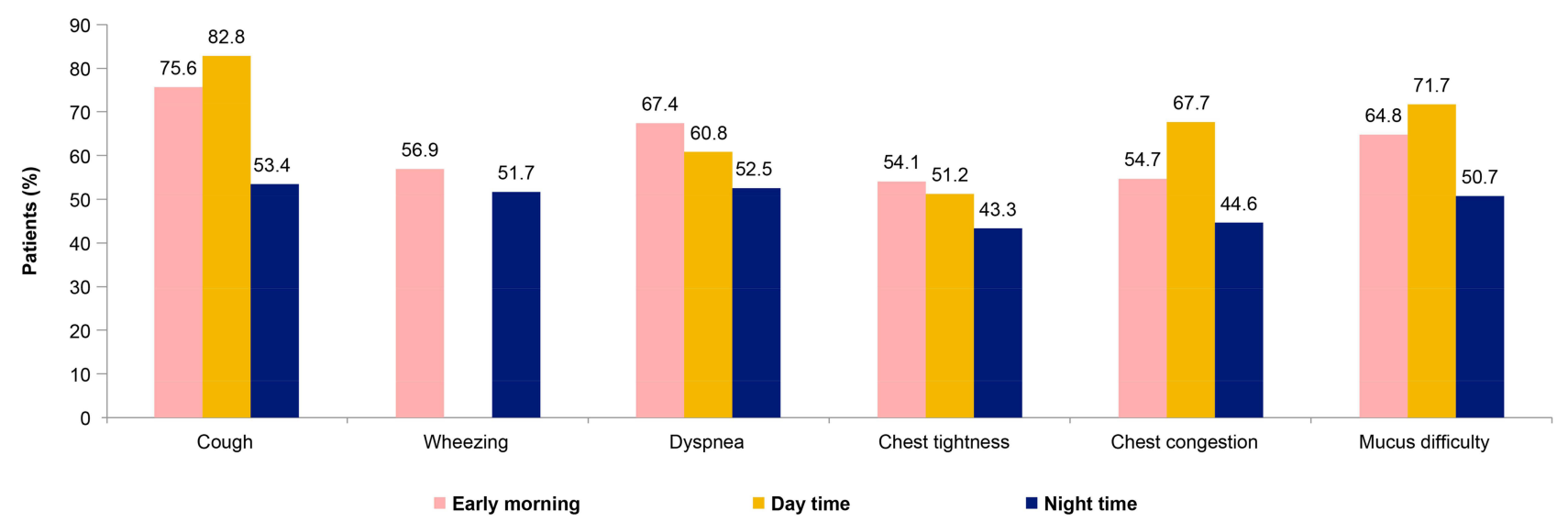

Figure 2 Prevalence of individual respiratory symptoms assessed by questionnaires corresponding for each part of the 24-h day EMSCI, NiSCI and E-RSTM:COPD. Note: Wheezing is not assessed with the derivative instrument of E-RS ${ }^{\mathrm{TM}}:$ COPD.

Abbreviations: 24-h, 24-hour; EMSCl, Early Morning Symptoms of COPD Instrument; E-RS ${ }^{\mathrm{TM}}$ :COPD, Evaluating Respiratory Symptoms in COPD; NiSCI, Nighttime Symptoms of COPD Instrument.

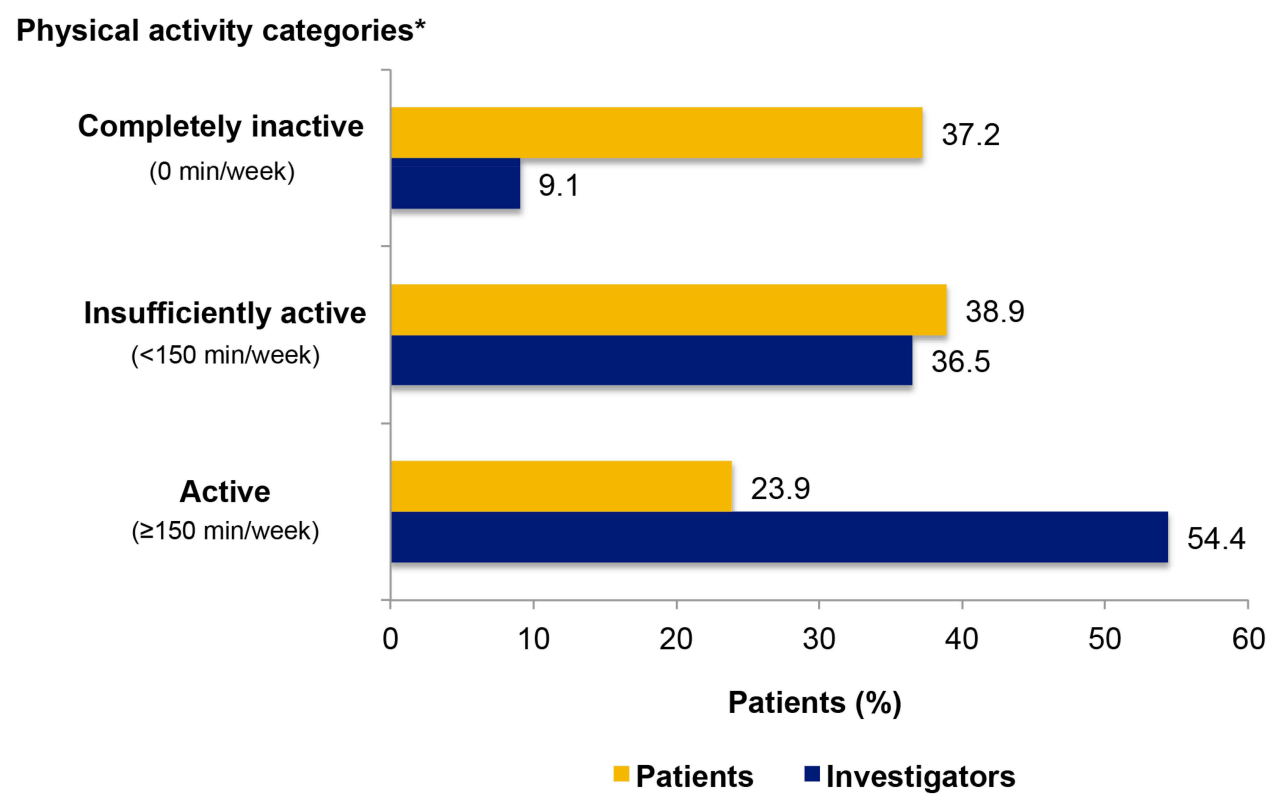

Figure 3 The physical activity level assessed by Investigators (clinical judgment) and self-assessed by patients (EVS questions).

Note: *Expressed in minutes/week of moderate to vigorous exercise.

Abbreviations: EVS, Exercise as Vital Sign; min, minutes.

of physical activity in advanced COPD disease and many patients have to reduce their effort just to avoid breathlessness. ${ }^{38}$ Dyspnea is a predictor factor for a low physical activity level, which was recently shown to fluctuate annually. ${ }^{39,40}$ Additionally, cough and fatigue influence the level of physical activity. ${ }^{41,42}$ However, a study investigating PAL in COPD patients prior to hospitalization reported that patients who performed regularly physical activity had less respiratory and extra-respiratory symptoms during an exacerbation. ${ }^{43}$ Such findings underline the importance of periodic evaluations of $R S$ and physical activity in COPD patients to early understand any changes and act in a timely fashion. A more intensive multifactorial approach that considers burden of symptoms, pre-existent level of physical activity, but also patients' goals, needs and living conditions is required for sustainable changes in patients' life with COPD.

In SPACE study, the physical activity was evaluated in a non-interventional manner through patients' perspective and physicians' evaluation. ${ }^{25}$ Patients were asked to answer to a questionnaire administered by their physician: YPAS, ${ }^{36}$ a validated tool for elderly patients covering 
Table 2 Physical Activity Results - YPAS Dimensions

\begin{tabular}{|l|l|}
\hline Characteristic & $\mathbf{N}=406$ \\
\hline YPAS checklist total time (min/week), mean (SD) & 1549.3 (I258.7) \\
\hline $\begin{array}{l}\text { Energy expenditure summary index (kcal/week), } \\
\text { mean (SD) }\end{array}$ & $5685.0(484 I .1)$ \\
\hline Vigorous activity index score, mean (SD) & $10.2(12.5)$ \\
\hline Leisurely walking index score, mean (SD) & $18.6(14.3)$ \\
\hline Moving index score, mean (SD) & $7.2(3.3)$ \\
\hline Standing index score, mean (SD) & $6.7(3.4)$ \\
\hline Sitting index score, mean (SD) & $2.6(1.1)$ \\
\hline Summary index, mean (SD) & $45.3(24.6)$ \\
\hline Seasonal adjustment score, mean (SD) & $1.0(0.1)$ \\
\hline
\end{tabular}

Abbreviations: SD, standard deviation; YPAS, Yale Physical Activity Survey.

a broad range of work, recreation and other physical activities. Romanian COPD stable patients spent less than 4 hours/day in any kind of activity, whereas healthy subjects or older patients usually spend between 4 to 9 hours/day. ${ }^{36,44}$ A score $<51$ in the YPAS summary index was proposed to help identifying the COPD patients at risk for sedentarism. ${ }^{45}$ The mean value of the summary index across our cohort is suggestive for a predominantly sedentary group, although the true percentage of patients with summary index $<51$ was not calculated in the country cohort. The results of YPAS are indicative of longer standing and sitting times and less time or effort spent in vigorous activities (in average 3-6 hours daily vs $<1$ hour a few times a week). A longer sitting time is correlated with a higher risk of mortality, independently of leisure time physical activity. ${ }^{46}$ In light of these findings, clinicians need to actively discuss with COPD patients about their daily routine and what type of activities they usually perform. This will help identifying sedentary behavior and inactivity patterns. Previous research has shown that interrupting long sitting times and replacing their sedentary behavior with low-intensity activities is beneficial for COPD patients. ${ }^{47-49}$ Yet, in reallife practice clinicians lack clear guidance on the most appropriate type, intensity and duration of physical activity for various categories of COPD patients and no strategies to promote effective physical activity interventions are available. $^{50,51}$

The SPACE study superposed the perception of COPD patients about their level of physical activity with the physicians' evaluation of every patient's PAL at the time of the visit. For the patient's self-assessment of PAL, EVS $^{35}$ was used. To not influence physicians' evaluation, the EVS category derived (active/insufficiently active/ inactive) was not displayed to Investigators in the electronic case report form at the time of study data entry. For the assessment of patients' PAL, Investigators were asked to use their clinical judgment without any instruction on how to explore the level of activity. The results in the Romanian set of data found that physicians overestimated the PAL of their patients, while stable COPD patients seemed to underestimate it. The discrepancy found indicates a different perception and perhaps relevance of physical activity for patients and physicians, which warrant further research from various angles. This finding also underlines the unmet need for simple and standardized instruments to help practitioners identifying the COPD patients at risk for inactivity as a preliminary step before using more objective measures for the PAL evaluation. A recent qualitative study from Australia ${ }^{52}$ showed that clinicians recognized the value of physical activity in COPD, but the evaluation of PAL in their patients was problematic. Additionally, they did not assess PAL, nor promoted activity at every consultation with COPD patients. Such insights from local practice are not available, but they would prove useful in understanding the constraints and goals of both parties. Initiating conversations about physical activity with patients would be a first step into this direction. Adapting best practices of existing, successful PR programs ${ }^{53,54}$ and other movement initiatives ${ }^{55}$ might be a preliminary phase together with assembling multidisciplinary task forces to further build, implement, and monitor relevant strategies, which are urgently needed at national level.

In addition, with the current Coronavirus Disease 2019 (COVID-19) pandemic and measures such as social distancing and quarantine taken to limit the spread of the disease, the COPD patients are at even higher risk for physical inactivity and sedentary behavior. ${ }^{56}$ All changes experienced at society level across the world brought additional challenges, calling for a different behavioral approach to foster patients' motivation to maintain a healthy, active lifestyle. ${ }^{57}$ Even though maintenance pulmonary rehabilitation can be safely delivered by means of communication technology, as shown by a recent Cochrane review, ${ }^{58}$ this is challenging to implement in Romania due to lack of resources and limited access to and/or proficiency in using new technology. 


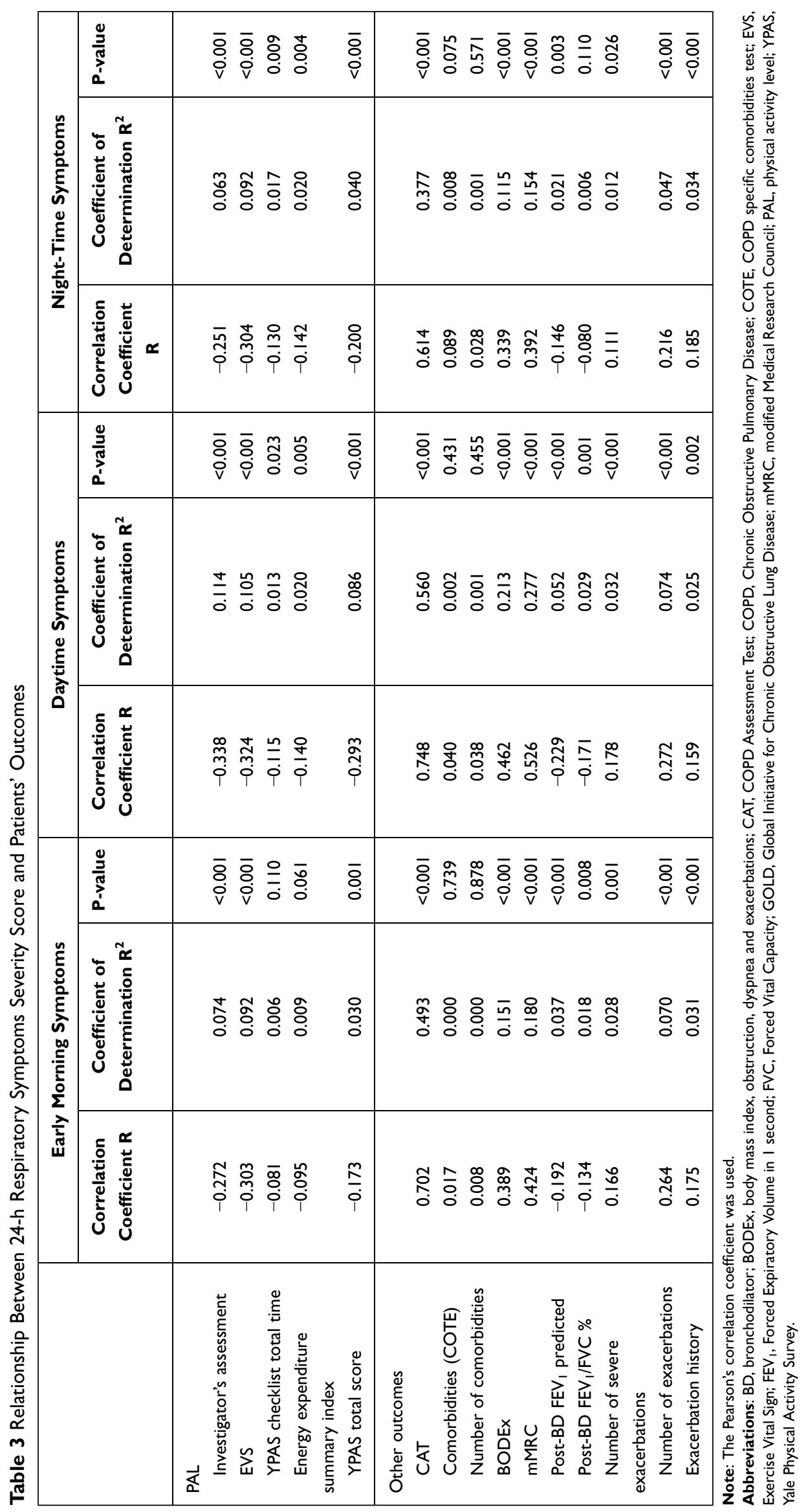


Table 4 Relationship Between Physical Activity and Patients' Outcomes

\begin{tabular}{|c|c|c|c|c|c|c|}
\hline & \multicolumn{3}{|c|}{ EVS } & \multicolumn{3}{|c|}{ YPAS Total Score } \\
\hline & $\begin{array}{c}\text { Correlation } \\
\text { Coefficient R }\end{array}$ & $\begin{array}{c}\text { Coefficient of } \\
\text { Determination } \mathbf{R}^{2}\end{array}$ & P-value & $\begin{array}{c}\text { Correlation } \\
\text { Coefficient R }\end{array}$ & $\begin{array}{c}\text { Coefficient of } \\
\text { Determination } \mathbf{R}^{2}\end{array}$ & P-value \\
\hline CAT & -0.291 & 0.085 & $<0.001$ & -0.353 & 0.125 & $<0.001$ \\
\hline Comorbidities (COTE) & 0.034 & 0.001 & 0.496 & -0.140 & 0.020 & 0.005 \\
\hline Number of comorbidities & 0.101 & 0.010 & 0.042 & -0.057 & 0.003 & 0.251 \\
\hline BODEX & -0.353 & 0.124 & $<0.001$ & -0.425 & 0.181 & $<0.001$ \\
\hline $\mathrm{mMRC}$ & -0.432 & 0.186 & $<0.001$ & -0.475 & 0.225 & $<0.001$ \\
\hline Post-BD FEVI predicted & 0.200 & 0.040 & $<0.001$ & 0.242 & 0.059 & $<0.001$ \\
\hline Post-BD FEVI/FVC \% & 0.152 & 0.023 & 0.002 & 0.187 & 0.035 & $<0.001$ \\
\hline $\begin{array}{l}\text { Number of severe } \\
\text { exacerbations }\end{array}$ & -0.074 & 0.005 & 0.137 & -0.197 & 0.039 & $<0.001$ \\
\hline Number of exacerbations & -0.147 & 0.021 & 0.003 & -0.226 & 0.051 & $<0.001$ \\
\hline Exacerbation history & -0.073 & 0.005 & 0.143 & -0.201 & 0.040 & $<0.001$ \\
\hline
\end{tabular}

Note: The Pearson's correlation coefficient was used.

Abbreviations: BD, bronchodilator; BODEx, body mass index, obstruction, dyspnea and exacerbations; CAT, COPD Assessment Test; COPD, Chronic Obstructive Pulmonary Disease; COTE, COPD specific comorbidities test; EVS, Exercise Vital Sign; FEV , Forced Expiratory Volume in I second; FVC, Forced Vital Capacity; GOLD, Global Initiative for Chronic Obstructive Lung Disease; mMRC, modified Medical Research Council; PAL, physical activity level; YPAS, Yale Physical Activity Survey.

Additionally, home exercises for patients with mild or moderate COPD proved to be difficult to implement and associated with a reduced patient's satisfaction even long before COVID-19 outbreak, as shown by a small observational study. ${ }^{59}$

Due to the observational nature of this study and its cross-sectional design, there are some inherent limitations. For example, in this set of data, no additional matched or stratified analyses were conducted to address confounding factors. Despite the significant relationships found between symptoms and physical activity and other outcomes, no causality can be proven. Another drawback of the study is the use of subjective measures only for the evaluation of the patients' PAL. Self-reported questionnaires are known as imprecise and subjective to recall bias. Additionally, they tend to be incongruent with objectively measured PAL and overestimate it. ${ }^{4,60}$ Wearing sensitive motion detectors for a pre-specified period would have influenced considerably the design of the study (prospective, interventional). Preliminary feasibility discussions indicated that in reallife practice, not all offices/clinics afford motion detectors, while for the 6-minutes walking test space may be problematic in small practices. Nevertheless, the results provided by the self-reported questionnaires emphasized that clinicians lack unsophisticated, standard instruments to assess and track COPD patients' PAL and/or inactivity patterns in real-life practice. Lastly, our paper characterizes the Romanian cohort of patients participating in a large international project and may be less generalizable. However, the main findings followed the trend of the entire study cohort with persistent 24-h RS, low level activity of physical activity and Investigators' overestimation of PAL in their patients.

\section{Conclusion}

Romanian stable COPD patients, despite being under treatment, are experiencing respiratory symptoms during day and night. These high 24-h day symptoms negatively correlate with a low level of physical activity. Despite the overall low physical activity level reported by patients, physicians considered their patients to be more active. The main clinical explanation is that practitioners may misjudge the true extent and effects of the patients' sedentary behavior. Simple tools to assess the physical activity in routine care are needed to allow the timely identification of inactivity patterns in all COPD patients, followed by more objective measures and tailored interventions within a comprehensive disease management program. 


\section{Abbreviations}

BD, bronchodilator; BODEx, body mass index, obstruction, dyspnea and exacerbations; CAT, COPD Assessment Test; COPD, Chronic Obstructive Pulmonary Disease; COTE, COPD specific comorbidities test; DT, day time; EM, early morning; EMSCI, Early Morning Symptoms of COPD Instrument; E-RS ${ }^{\mathrm{TM}}$ :COPD, Evaluating Respiratory Symptoms in COPD; EVS, Exercise Vital Sign; FEV 1 , Forced Expiratory Volume in 1 second; FVC, Forced Vital Capacity; GOLD, Global Initiative for Chronic Obstructive Lung Disease; mMRC, modified Medical Research Council; NiSCI, Nighttime Symptoms of COPD Instrument; NT, night-time; PAL, physical activity level; RS, respiratory symptoms; SD, standard deviation; YPAS, Yale Physical Activity Survey.

\section{Data Sharing Statement}

The basic data are available upon written request to the study Sponsor.

\section{Ethics Approval and Informed Consent}

In Romania, the study was approved by the National Bioethics Committee of Medicines and Medical Devices (approval number 29SNI/21.11.2016). Written informed consent was obtained from all patients before enrolment in the study.

\section{Acknowledgments}

Medical writing support (in the form of writing assistance, assembling tables and figures, collating authors' comments, grammatical editing and referencing) was provided by Ana Maria Iordan, MD of MedInteractiv Plus (Bucharest, Romania) and funded by AstraZeneca. An abstract based on this cohort results was presented at the Chest Annual Meeting 2019. The poster's abstract was published in the "CHEST 2019 Annual Meeting Abstracts" issue in CHEST: https://doi.org/10.1016/j. chest.2019.08.952.

\section{Author Contributions}

RR, OCA, PP made substantial contributions to acquisition of data and interpretation of data. FM and SA coordinated the acquisition of data and made substantial contributions to interpretation of data. All authors took part in drafting the article or revising it critically for important intellectual content; agreed to submit to the current journal; gave final approval of the version to be published; and agree to be accountable for all aspects of the work.

\section{Funding}

This study was funded by AstraZeneca. The study Sponsor had a role in the study design, data analysis, and data interpretation.

\section{Disclosure}

$\mathrm{SA}$ is employee of AstraZeneca. All the other authors have no competing interests to declare in regard to this study.

\section{References}

1. Global Initiative for Chronic Obstructive Lung Disease. Global initiative for the diagnosis, prevention and management of chronic obstructive pulmonary disease, report 2021. Available from: https:// goldcopd.org/wp-content/uploads/2020/11/GOLD-REPORT-2021-v1. 1-25Nov20_WMV.pdf. Accessed April 26, 2021.

2. Vestbo J, Hurd SS, Agustí AG, et al. Global strategy for the diagnosis, management, and prevention of chronic obstructive pulmonary disease: GOLD executive summary. Am J Respir Crit Care Med. 2013;187(4):347-365. doi:10.1164/rccm.201204-0596PP

3. Global Initiative for Chronic Obstructive Lung Disease. Global initiative for the diagnosis, prevention and management of chronic obstructive pulmonary disease, report 2017. Available from: https:// goldcopd.org/wp-content/uploads/2017/02/wms-GOLD-2017-

FINAL.pdf. Accessed November 3, 2020.

4. Partridge MR, Karlsson N, Small IR. Patient insight into the impact of chronic obstructive pulmonary disease in the morning: an internet survey. [published correction appears in Curr Med Res Opin. 2012;28(8):1405]. Curr Med Res Opin. 2009;25(8):2043-2048. doi:10.1185/03007990903103006

5. Kessler R, Partridge MR, Miravitlles M, et al. Symptom variability in patients with severe COPD: a pan-European Cross-Sectional Study. Eur Respir J. 2011;37(2):264-272. doi:10.1183/09031936.00051110

6. Jenkins CR, Celli B, Anderson JA, et al. Seasonality and determinants of moderate and severe COPD exacerbations in the TORCH Study. Eur Respir J. 2012;39(1):38-45. doi:10.1183/09031936.00194610

7. Miravitlles M, Worth H, Soler Cataluña JJ, et al. Observational study to characterise 24-hour COPD symptoms and their relationship with patient-reported outcomes: results from the ASSESS Study. Respir Res. 2014;15(1):122. doi:10.1186/s12931-014-0122-1

8. Miravitlles M, Izquierdo JL, Esquinas C, et al. The variability of respiratory symptoms and associated factors in COPD. Respir Med. 2017;129:165--172. doi:10.1016/j.rmed.2017.06.017

9. Roche N, Chavannes NH, Miravitlles M. COPD symptoms in the morning: impact, evaluation and management. Respir Res. 2013;14 (1):112. doi:10.1186/1465-9921-14-112

10. Tsiligianni I, Metting E, van der Molen T, Chavannes N, Kocks J. Morning and night symptoms in primary care COPD patients: a cross-sectional and longitudinal study. An UNLOCK study from the IPCRG. NPJ Prim Care Respir Med. 2016;26(1):16040. doi:10.1038/ npjpcrm.2016.40

11. van Buul AR, Kasteleyn MJ, Chavannes NH, Taube C. Association between morning symptoms and physical activity in COPD: a systematic review. Eur Respir Rev. 2017;26(143):160033. doi:10.1183/16000617.0033-2016

12. Kapella MC, Larson JL, Covey MK, Alex CG. Functional performance in chronic obstructive pulmonary disease declines with time. Med Sci Sports Exerc. 2011;43(2):218-224. doi:10.1249/ MSS.0b013e3181eb6024 
13. Garcia-Aymerich J, Lange P, Benet M, Schnohr P, Antó JM. Regular physical activity reduces hospital admission and mortality in chronic obstructive pulmonary disease: a Population Based Cohort Study. Thorax. 2006;61(9):772-778. doi:10.1136/thx.2006.060145

14. Gimeno-Santos E, Frei A, Steurer-Stey C, et al. Determinants and outcomes of physical activity in patients with COPD: a systematic review. Thorax. 2014;69(8):731-739. doi:10.1136/thoraxjnl-2013204763

15. ZuWallack R, Esteban C. Understanding the impact of physical activity in COPD outcomes: moving forward. Eur Respir J. 2014;44(5):1107-1109. doi:10.1183/09031936.00151014

16. Mihaltan FD, Nedelcu RE, Ionescu A, Nemes R. Romanian awareness campaign on the WORLD COPD day. Eur Respir $J$ 2015;46(supp159):PA1060. doi:10.1183/13993003.congress-2015. PA1060

17. Nedelcu RE, Mihaltan FD, Ulmeanu R. Romanian awareness and screenings for obstructive airway disease - world asthma and COPD day 2017. Eur Res J. 2018;52(supp162):PA4420. doi:10.1183/13993003.congress-2018.PA4420

18. Tudorache V, Oancea C, Avram C, Fira-Mlădinescu O. Changes in physical activity in healthy people and COPD patients. Wien Klin Wochenschr. 2014;126(1-2):30-35. doi:10.1007/s00508-013-0452-x

19. Bertici N, Fira-Mlădinescu O, Oancea C, Tudorache V. The usefulness of pedometry in patients with chronic obstructive pulmonary disease. Multidiscip Respir Med. 2013;8(1):7. doi:10.1186/20496958-8-7

20. Mihălţan F, Ungureanu D. Correlation between patient perception of the ability to perform morning activities and findings on clinical examination in COPD patients in Romania. Pneumologia. 2016;65 (3):138-141.

21. Troosters T, Bourbeau J, Maltais F, et al. Enhancing exercise tolerance and physical activity in COPD with combined pharmacological and non-pharmacological interventions: PHYSACTO Randomised, Placebo-Controlled Study design. BMJ Open. 2016;6(4):e010106. doi:10.1136/bmjopen-2015-010106

22. Kantorowksi A, Wan ES, Homsy D, Kadri R, Richardson CR, Moy ML. Determinants and outcomes of change in physical activity in COPD. ERJ Open Res. 2018;4(3):00054-2018. doi:10.1183/ 23120541.00054-2018

23. Watz H, Pitta F, Rochester CL, et al. An official European respiratory society statement on physical activity in COPD. Eur Respir J. 2014;44(6):1521-1537. doi:10.1183/09031936.00046814

24. Watz H, Waschki B, Meyer T, Magnussen H. Physical activity in patients with COPD. [published correction appears in Eur Respir J. 2010;36(2):462]. Eur Respir J. 2009;33(2):262-272. doi:10.1183/ 09031936.00024608

25. Mihaltan F, Adir Y, Antczak A, et al. Importance of the relationship between symptoms and self-reported physical activity level in stable COPD based on the results from the SPACE study. Respir Res. 2019;20(1):89. doi:10.1186/s12931-019-1053-7

26. Divo M, Cote C, de Torres JP, et al. Comorbidities and risk of mortality in patients with chronic obstructive pulmonary disease. Am J Respir Crit Care Med. 2012;186(2):155-161. doi:10.1164/ rccm.201201-0034OC

27. Soler-Cataluna JJ, Martínez-García MA, Sánchez LS, et al. Severe exacerbations and BODE index: two independent risk factors for death in male COPD patients. Respir Med. 2009;103(5):692-699. doi:10.1016/j.rmed.2008.12.005

28. Lee H, Kim J, Tagmazyan K. Treatment of stable chronic obstructive pulmonary disease: the GOLD guidelines. Am Fam Physician. 2013;88(10):655-63, 663B-F.

29. Bestall JC, Paul EA, Garrod R, Garnham R, Jones PW, Wedzicha JA. Usefulness of the Medical Research Council (MRC) dyspnoea scale as a measure of disability in patients with chronic obstructive pulmonary disease. Thorax. 1999;54(7):581-586. doi:10.1136/ thx.54.7.581
30. Jones JW, Harding G, Berry P, Wiklund I, Chen WH, Kline Leidy N. Development and first validation of the COPD assessment test. Eur Respir J. 2009;34(3):648-654. doi:10.1183/09031936.00102509

31. Stephenson JJ, Cai Q, Mocarski M, Tan H, Doshi JA, Sullivan SD. Impact and factors associated with nighttime and early morning symptoms among patients with chronic obstructive pulmonary disease. Int J Chron Obstruct Pulmon Dis. 2015;10:577-586. doi:10.2147/COPD.S76157

32. Leidy NK, Sexton CC, Jones PW, et al. Measuring respiratory symptoms in clinical trials of COPD: reliability and validity of a daily diary. Thorax. 2014;69(5):443-449. doi:10.1136/thoraxjnl-2013204428

33. Mocarski M, Zaiser E, Trundell D, Make BJ, Hareendran A. Evaluation of the psychometric properties of the nighttime symptoms of COPD instrument. Int $J$ Chron Obstruct Pulmon Dis. 2015;10:475-487. doi:10.2147/COPD.S75776

34. Coleman KJ, Ngor E, Reynolds K, et al. Initial validation of an exercise "vital sign" in electronic medical records. Med Sci Sports Exerc. 2012;44(11):2071-2076. doi:10.1249/MSS.0b013e3182 $630 \mathrm{ec} 1$

35. Grant RW, Schmittdiel JA, Neugebauer RS, Uratsu CS, Sternfeld B. Exercise as a vital sign: a quasi-experimental analysis of a health system intervention to collect patient-reported exercise levels. $J$ Gen Intern Med. 2014;29(2):341-348. doi:10.1007/s11606-013-2693-9

36. Dipietro L, Caspersen CJ, Ostfeld AM, Nadel ER. A survey for assessing physical activity among older adults. Med Sci Sports Exerc. 1993;25(5):628-642. doi:10.1249/00005768-199305000-00016

37. Di Marco F, Santus P, Scichilone N, et al. Symptom variability and control in COPD: advantages of dual bronchodilation therapy. Respir Med. 2017;125:49-56. doi:10.1016/j.rmed.2017.03.001

38. O’Donnell DE. Hyperinflation, dyspnea, and exercise intolerance in chronic obstructive pulmonary disease. Proc Am Thorac Soc. 2006;3 (2):180-184. doi:10.1513/pats.200508-093DO

39. Albarrati AM, Gale NS, Munnery MM, Cockcroft JR, Shale DJ. Daily physical activity and related risk factors in COPD. BMC Pulm Med. 2020;20(1):60. doi:10.1186/s12890-020-1097-y

40. Sánchez-Martínez MP, Bernabeu-Mora R, García-Vidal JA, et al. Patterns and predictors of low physical activity in patients with stable COPD: a Longitudinal Study. Ther Adv Respir Dis. 2020;14:1753466620909772. doi:10.1177/1753466620909772

41. Mantoani LC, Rubio N, McKinstry B, MacNee W, Rabinovich RA. Interventions to modify physical activity in patients with COPD: a systematic review. Eur Respir J. 2016;48(1):69-81. doi:10.1183/ 13993003.01744-2015

42. Cook N, Gey J, Oezel B, et al. Impact of cough and mucus on COPD patients: primary insights from an exploratory study with an online patient community. Int $J$ Chron Obstruct Pulmon Dis. 2019;14:1365-1376. doi:10.2147/COPD.S202580

43. López-López L, Torres-Sánchez I, Romero-Fernández R, GranadosSantiago M, Rodríguez-Torres J, Valenza MC. Impact of previous physical activity levels on symptomatology, functionality, and strength during an acute exacerbation in COPD patients. Healthcare (Basel). 2018;6(4):139. doi:10.3390/healthcare6040139

44. De Abajo S, Larriba R, Marquez S. Validity and reliability of the Yale physical activity survey in Spanish elderly. J Sports Med Phys Fitness. 2001;41(4):479-485.

45. Donaire-Gonzales D, Gimeno-Santos E, Serra I, et al. Validación del cuestionario de actividad física de Yale en pacientes con enfermedad pulmonar obstructiva crónica [validation of the Yale physical activity survey in chronic obstructive pulmonary disease patients]. Arch Bronconeumol. 2011;47(11):552-560. doi:10.1016/j.arbres.2011. 07.002

46. Katzmarzyk PT, Church TS, Craig CL, Bouchard C. Sitting time and mortality from all causes, cardiovascular disease, and cancer. Med Sci Sports Exerc. 2009;41(5):998-1005. doi:10.1249/MSS.0b013e3181 930355 
47. Lewthwaite H, Effing TW, Olds T, Williams MT. Physical activity, sedentary behaviour and sleep in COPD guidelines: a systematic review. Chron Respir Dis. 2017;14(3):231-244. doi:10.1177/ 1479972316687224

48. Hartman JE, Boezen HM, de Greef MH, Ten Hacken NH. Physical and psychosocial factors associated with physical activity in patients with chronic obstructive pulmonary disease. Arch Phys Med Rehabil. 2013;94(12):2396-2402.e7. doi:10.1016/j.apmr.2013.06.029

49. Lewthwaite H, Effing TW, Lenferink A, Olds T, Williams MT. Improving physical activity, sedentary behaviour and sleep in COPD: perspectives of people with COPD and experts via a Delphi approach. PeerJ. 2018;6:e4604. doi:10.7717/peerj.4604

50. Burge AT, Cox NS, Abramson MJ, Holland AE. Interventions for promoting physical activity in people with chronic obstructive pulmonary disease (COPD). Cochrane Database Syst Rev. 2020;4(4): CD012626. doi:10.1002/14651858.CD012626.pub2

51. Araújo A. COPD and physical activity. Rev Port Pneumol. 2016;22 (5):299-301. doi:10.1016/j.rppnen.2016.02.009

52. Lahham A, Burge AT, McDonald CF, Holland AE. How do healthcare professionals perceive physical activity prescription for community-dwelling people with COPD in Australia? A Qualitative Study. BMJ Open. 2020;10(8):e035524. doi:10.1136/bmjopen-2019035524

53. Postolache P, Pop CS, Nemes RM, Nitu FM. Pulmonary rehabilitation in COPD. Arch Balk Med Union. 2015;50(2):262-267.

54. Royal College of Physicians. National Asthma and COPD Audit Programme (NACAP) [homepage on the Internet]. United Kingdom: National Asthma and COPD Audit Programme (NACAP): pulmonary rehabilitation workstream; 2020. Available from: https://www.rcplondon.ac.uk/projects/national-asthma-andcopd-audit-programme-nacap-pulmonary-rehabilitation-workstream. Accessed July 26, 2021.
55. Faculty of Sport and Exercise Medicine UK. Moving Medicine [homepage on the Internet]. United Kingdom: Consultation Guides - COPD; 2021. Available from: https://movingmedicine.ac.uk/consul tation-guides/condition/adult/copd/. Accessed July 26, 2021.

56. Hall G, Laddu DR, Phillips SA, Lavie CJ, Arena R. A tale of two pandemics: how will COVID-19 and global trends in physical inactivity and sedentary behavior affect one another? Prog Cardiovasc Dis. 2020;2021(64):108-110. doi:10.1016/j.pcad.2020.04.005

57. Karloh M, Sousa Matias T, Fleig Mayer A. The COVID-19 pandemic confronts the motivation fallacy within pulmonary rehabilitation programs. COPD. 2020;17(4):343-345. doi:10.1080/15412555.2020. 1790511

58. Cox NS, Dal Corso S, Hansen H, et al. Telerehabilitation for chronic respiratory disease. Cochrane Database Syst Rev. 2021;1(1): CD013040. doi:10.1002/14651858.CD013040.pub2

59. Balteanu M, Kamal C, Kamal D, Postolache P, Traistaru R. Pulmonary rehabilitation in COPD patients. Med Surg J. 2018;122 (3):474-483.

60. Thyregod M, Bodtger U. Coherence between self-reported and objectively measured physical activity in patients with chronic obstructive lung disease: a systematic review. Int J Chron Obstruct Pulmon Dis. 2016;11:2931-2938. doi:10.2147/COPD.S116422

\section{Publish your work in this journal}

The International Journal of COPD is an international, peer-reviewed journal of therapeutics and pharmacology focusing on concise rapid reporting of clinical studies and reviews in COPD. Special focus is given to the pathophysiological processes underlying the disease, intervention programs, patient focused education, and self management protocols. This journal is indexed on PubMed Central, MedLine and CAS. The manuscript management system is completely online and includes a very quick and fair peer-review system, which is all easy to use. Visit http://www.dovepress.com/testimonials.php to read real quotes from published authors. 